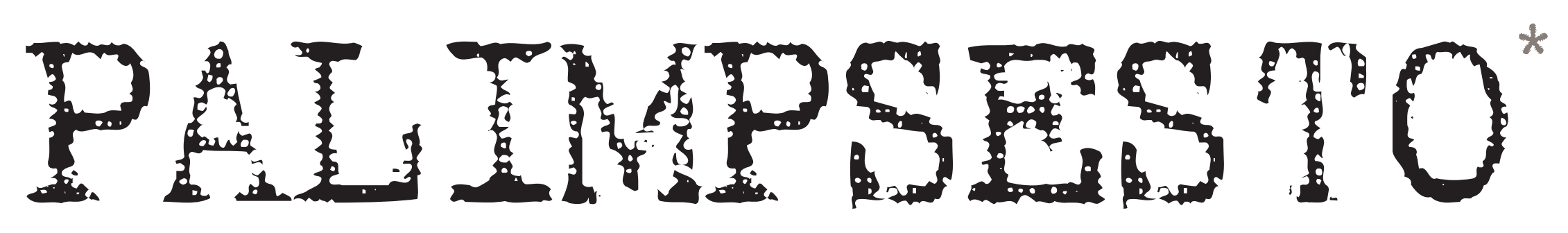

1021 Entrevista. Le Corbusier, todavía I Ariadna Perich y Roger Such I

BAGATELAS EN FALTRIQUERA

1051 Debate. Focus d'infiltració. Una jornada de debat a la natura I Jaume Prat |

06l Efímero. Piso Piloto. Medellín-Barcelona I Josep Bohigas y Anna Vergés I

08І Efímero. Cuadernos de faltriquera. Recorridos perceptivos de un mundo íntimo I Iñaki Baquero Riazuelo I

I10I Proyecto y Material. Hult International Business School I Sergison Bates architects I

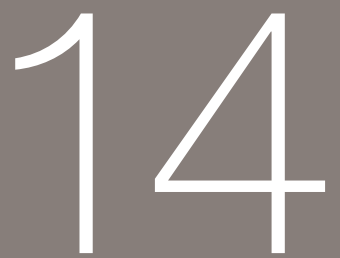

1121 Investigación. Ritmos a ras de suelo I Eulàlia Gomez Escoda |

4 EUR

113I Investigación. Un recorrido por los planos de suelo miesianos I Jordi Ros I

2015

\section{Le Corbusier, todavía}

Ariadna Perich y Roger Such

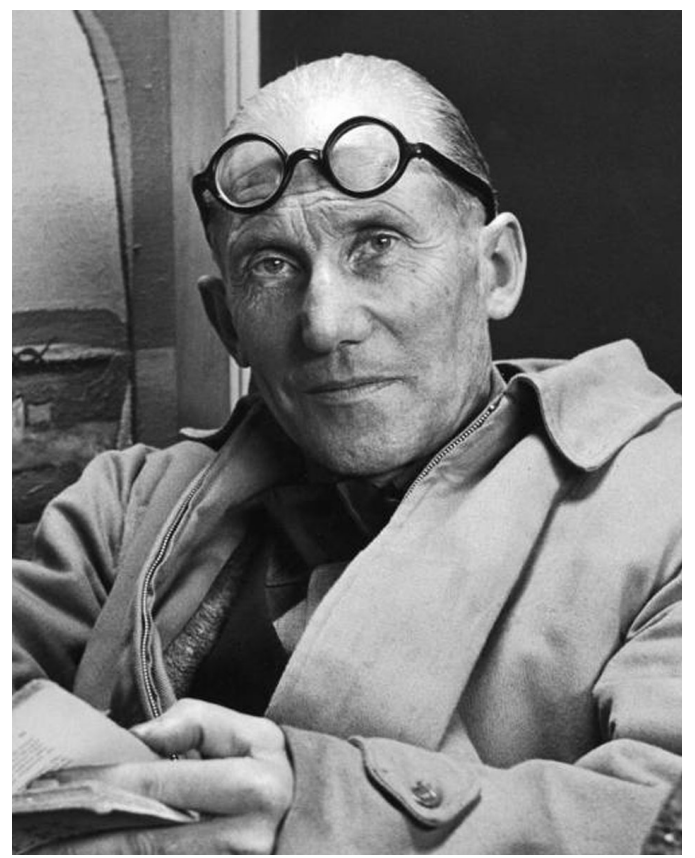

Cincuenta años después de la muerte de Le Corbusier, se celebra en la ETSA Valencia el Congreso Internacional "LC2015: Le Corbusier, 50 years later". Este encuentro certifica la capacidad de sugestión que hoy en día sigue despertando la figura de Le Corbusier entre investigadores. Y aunque entre el entorno académico empiezan a sentirse voces cada vez más críticas que afirman haber llegado a un cierto agotamiento del personaje, su presencia en el contexto arquitectónico sigue siendo abundante y actual, lo cual nos lleva a preguntar sobre el porqué de su longevidad crítica.

Este artículo se presenta como una crónica del congreso, a medio camino entre la reseña crítica y la selección personal de extractos. El lector puede escoger el modo como recorrerla, ya sea de manera lineal, a través del texto comentado, o bien de forma intercalada, mediante la selección personal de citas escogidas entre las más de 130 aportaciones de todo el congreso.

\section{Cuadernos de faltriquera}

Recorridos perceptivos de un mundo íntimo

Dibujos de Manolo Baquero

Inaki Baquero Riazuelo

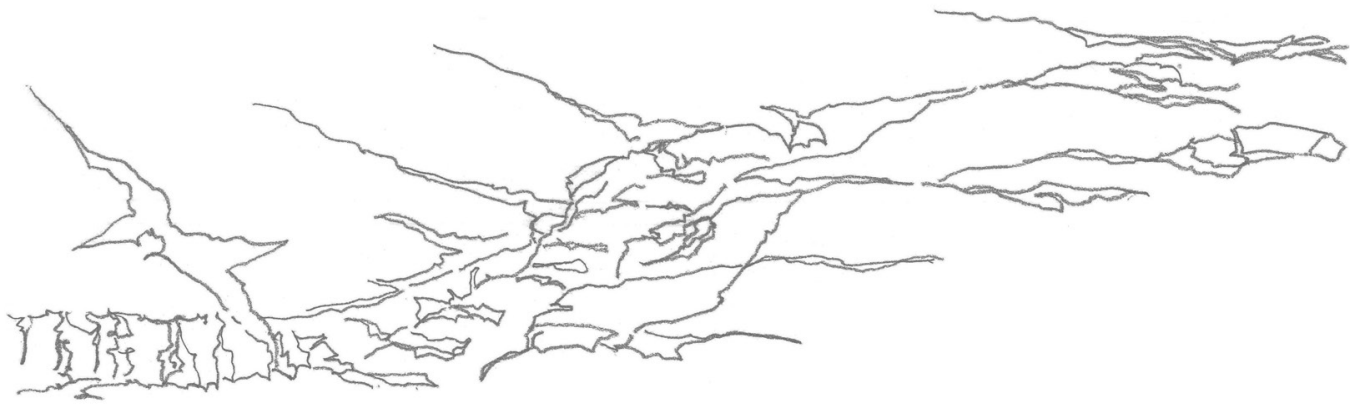

\section{Hult International Business School}

Sergison Bates architects

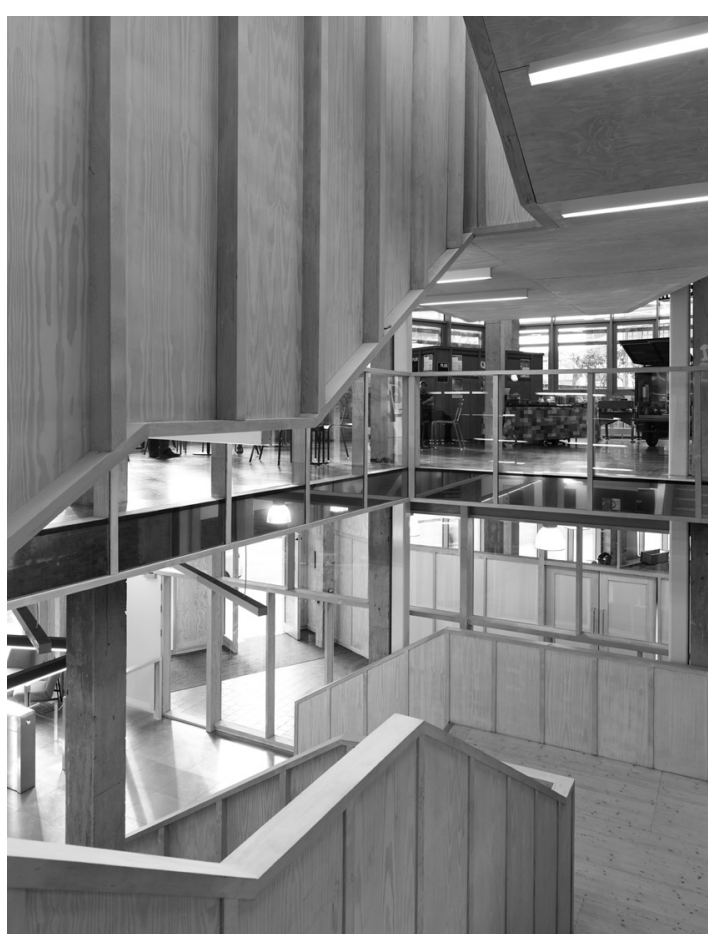

The former St. George's Brewery, a historic landmark from the Victorian era, was identified as an exciting location for Hult's first UK undergraduate campus.

The building had been extended recently with an open concrete-framed shell, generating a rich mixture of spatial characters. We made an "inventory of rooms" that plotted their scale, material and atmosphere. Our ambition was to emphasise, complement and enhance their character, drawing attention to ceiling height differences, column sizes and existing surfaces, and to organise the Campus so that students, teachers and staff would be brought into contact with a variety of spaces throughout the day.

\section{Piso Piloto Medellín-Barcelona}

Josep Bohigas y Anna Vergés 